\title{
El Simbolismo en Las Montañas del Oro*
}

$\mathrm{H}^{\mathrm{L}}$ poeta es Dios y Dios es el poeta. Así se anuncia Leopoldo Lu1 gones en Las montañas del oro, su primer libro de poesías, que apareció en i 897 , cuando el poeta tenía veintitrés años. El libro consta de una introducción y tres ciclos, organizados alrededor de una idea central.

En la "Introducción" el poeta opone dos ideas: la razón y la fe. Para él la una excluye la otra y el poeta se ve necesitado de escoger. No tarda en explicar que la "fe es la suprema reveladora" (57). Nótese que al rechazar la razón como modo de pensar, Lugones adhiere a la tradición romántica. El último verso de la "Introducción" afirma esta actitud lugoniana de escoger la fe cuando escribe "y decidi ponerme de parte de los astros" (60). Advierte y reitera que las consecuencias de esta decisión son arduas y que es un camino difícil, pero que al fin vale la pena.

Los tres ciclos que siguen a la "Introducción" están dedicados a expresar el deseo de seguir el camino de la fe y el del sufrimiento por el cual es necesario pasar antes de alcanzar el premio final. El "Primer ciclo" expone el deseo del poeta de conseguir el ideal, el "Segundo ciclo" representa el sufrimiento necesario para realizar lo ideal, y el "Tercer ciclo" describe la belleza del deseo conseguido. Cada ciclo ensancha más la esfera de la experiencia; así, el "Primer ciclo" describe los dolores personales del poeta mismo; el "Segundo ciclo" se extiende hasta incluir el martirio de toda la naturaleza; el "Tercer ciclo" incluye toda la humanidad en la marcha de la historia. Empezando con lo personal, Las montañas del oro va abriéndose cada vez más hasta incluirlo todo.

La estructura del libro está tan bien organizada que merece mencionarse. Además tiene mucho que ver con la idea central del poemario.

* Leopoldo Lugones, Obras poéticas completas, Prólogo de Pedro Miguel Obligado (Madrid, M. Aguilar, editor 1959). Todas las citas de Lugones son del mismo libro y la página a que se refiere la cita se encontrará al final de la cita misma. 
Para hacer un paralelo con la música, diremos que Las montañas del oro es como una orquesta sinfónica. Cada instrumento entra en la composición y en sí lleva la melodía. Igual que las notas que entran en una partitura para cada instrumento, los símbolos de esta poesía conducen hacia un fin armonioso. Sin embargo, sólo en el conjunto se aprecia todo el valor de la pieza. En la "Introducción" Lugones menciona a cuatro poetas, a quienes estima mucho. Son Hugo, Dante, Whitman y Homero. Estos cuatro poetas corresponden a la "Introducción" y a los tres ciclos que siguen. Hugo está representado en la "Introducción". La noche del "Primer ciclo" recuerda el "Infierno" de Dante. En cierto modo, el es. cribir sobre la Naturaleza en el "Segundo ciclo" recuerda a Whitman, aunque el punto de vista de los dos poetas es muy distinto. Whitman describe la alegría de todos los aspectos de una nación nueva, en los cuales figura la Naturaleza. Lugones describe el sufrimiento de la $\mathrm{Na}$ turaleza, pero con la misma idea de Whitman, de que la Naturaleza forma una parte de la visión total de la vida. El "Tercer ciclo" corresponde a Homero. Dice Lugones, en la "Introducción": "Tan de cerca le ha hablado Dios, que él [Homero] habla lo mismo" (56). A finales del "Tercer ciclo" escribe, "... los hombres miran a Dios de frente" (IO2). En el primer caso Homero y Dios están en un mismo nivel, y en el segundo, todos los hombres y Dios están cara a cara. Como otros ejemplos que muestran la buena construcción del poema, se ve en la "Introducción" que hay columnas y que hay una "Columna blasfema" (60). Las coIumnas se convierten en torres en el "Tercer ciclo". Entre las torres Lugones menciona a "Babel con su torre de blasfemia" (97). Un caballo que suda a causa de su cansancio en el "Primer ciclo" (63) se convierte en un "gran caballo negro al cual no se ve sudar" (99) en el "Tercer ciclo". Otro elemento que entra, sale y reaparece es la historia del martirio de Jesucristo, por ejemplo. En fin, que todos los símbolos que intervienen para llevar el ideario a su punto culminante del "Tercer ciclo" se enlazan en un conjunto de partes indispensables para llegar a la idea central y muestran la construcción consciente que ha dado el poeta a su primer libro de versos.

Lugones propone en Las montañas del oro que el poeta es como un símbolo para salvar al resto del mundo. Pero además de esto, toda la humanidad, toda la Naturaleza desde lo más alto hasta lo más bajo, trabaja o sufre para purificarse. En la purificación del uno está la salvación del otro. Cuando una parte del conjunto triunfa después de sufrir, es que todas las partes han sufrido y han triunfado. Sin embargo, esta 
idea se ve presentada pero no lograda del todo. Uno tiene la impresión de que, a pesar de creer en la purificación mutua de toda la tierra, el poeta todo el tiempo está en su torre mirando el desarrollo de su idea, pero sin participar en ella. La idea de que todo está formado de carne y de espíritu, de que tras el martirio por el cual pasa todo, y de que después de la noche del sufrimiento viene la luz de la salvación, se ve ex. presz da claramente en los símbolos que usa Lugones.

En la clasificación de los símbolos* de Las montañas del oro hemos hallado seis tipos o categorías. Son: I) símbolos ascendentes; 2) símbolos de lo ideal; 3) símbolos de fuerza y movimiento; 4) símbolos de sufrimiento; 5) símbolos de lo bajo; y 6) símbolos que se refieren a estímulos para sufrir.

Hay que considerar cómo los símbolos se usan en las cuatro partes del libro. La mayoría de ellos se usan a través de todo el libro, pero según los versos en que se encuentran se entiende mejor el pensamiento de Lugones.

* Usamos aquí la palabra "símbolo" dentro del concepto elaborado por las escuelas intuicionistas y simbolistas - de Bergson a Cassirer- y que podría resumirse en la afirmación de Wilbur Marshall Urban, según la cual el símbolo es "... siempre algún objeto de intuición, perceptiva e imaginativa, que sugiere o encarna un contenido ideal". Para Fiser. (E. Fiser, Le Symbole Littéraire: Essai sur la signification du symbole cbez Wagner, Baudelaire, Mallarmé, Bergson et Marcel Proust, Paris, sin fecha. pp. 33-34), el artista simbolista “... doit se plonger la pureté d'une vision desintéressée, degagée de tout symbole conventionnel et général, que nous cache la vérité profonde de l'esprit et de la nature... Le symbole est donc une gêne à la compréhension de la véritable nature". En la escuela simbolista francesa el símbolo parece identificarse más con las sugerencias. Interpretando este criterio, Bergson ha llegado a decir que un símbolo no tiene el poder de ser la esencia misma de la vida; sólo puede sugerirla. El símbolo es una sugerencia de la vida y el poeta evoca la vida merced a un símbolo. En esta sugerencia, en esta evocación, se funda el carácter dinámico del simbolismo moderno. El último grado de este simbolismo parece ser la sinestesia. Según Johansen (Svend Johansen, Le Symbolisme, Copenhague, 1945, pp. 32-33). "Les deux phémonènes qui conditionnent l'existence de la synesthésie sont l'association et l'analogie. Quand deux sensations ont été fortement associées dans notre imagination, non seulment l'une nous fait penser á l'autre; leur asociation devient vraiment une combinaison". El mismo Johansen afirma que "l'antithèse assimilaire est de loin la plus fréquente chez les vrais symbo. listes, ce qui est naturel, puisque c'est une forme de construction qui est directement née du besoin de syntbèse du symbole" (p. 126). Como podrá compren. derse la defínición definitiva del símbolo resulta difícil de lograr y estaria condicionada a la evolución histórica del concepto de lo simbólico. En todo caso el símbolo poético es siempre una creación que, partiendo de la realidad, agrega un sentido a las cosas, que es lo que el poeta propone como su visión estética del mundo (véase Martin Foss, Symbol and Metaphor in Human Experience, Princeton, 1949, y William York Tindall, The Literary Symbol, New York, 1955). 


\section{Simbolos Ascendentes.}

Los símbolos ascendentes están expresados por columnas, torres y montañas. Físicamente todos suben y así señalan el premio que está en lo alto. La montaña tiene una cuesta, que es ardua. La cuesta simboliza el martirio, experiencia necesaria antes de alcanzar lo deseado, que está arriba. Como se ve, el poeta mismo se compone de espíritu y carne:

Él [el poeta] tiene su cabeza junto a Dios, como todos, Pero su carne es fruto de los cósmicos lodos

De la vida. Su espíritu del mismo yugo es siervo.

Pero en su frente brilla la integridad del Verbo (55).

Los símbolos también tienen una mezcla. Las torres son de oro pero a la vez hay una que es blasfema. La humanidad, que está simbolizada por torres y columnas, se compone de lo ideal y de lo real, de oro y de blasfemia. La montaña igualmente consta de este dualismo. En un poema del "Segundo ciclo" titulado "El carbón" (84-85) se ve que el cuerpo de la montaña es ejemplo de la creencia del poeta de que hay que sufrir para purificarse. La montaña tiene en sí el carbón. Tras el martirio de la montaña el carbón se transforma en diamantes: "Y aquel gran corazón mártir de los montes de la tierra - que en su herido seno guarda, transformadas en diamantes -, almas de estrellas..." (85). Gracias al fuego que quema el carbón, la montaña tiene que sufrir, pero lo vil llega a ser lo bueno y valioso. Con esta imagen tan gráfica Lugones muestra que uno alcanza el ideal sólo después de sufrir y que dentro de uno mismo está el ideal, pero no triunfa sin el martirio.

En esta clasificación de símbolos ascendentes están también los representados por alas y pájaros. Ambos son símbolos del vuelo hacia to ideal. Es interesante notar que Lugones usa los símbolos de torre y de ala con mucho más frecuencia en el "Tercer ciclo" que en los otros. Aquello que indica el ideal está donde se describe como ya alcanzado. Es significativo que en el "Tercer ciclo" el poeta, repetidas veces, se describe así: "Y mi alma - golondrina ideal — desde su torte sigue mirando". El poeta ha alcanzado el ideal en el último ciclo y por eso se pone en lo alto (la torre), como un pájaro que, por virtud de su vuelo, ha alcanzado la altura buscada. 


\section{Simbolos DE LO IDEAI.}

Los símbolos que significan lo ideal son los de la segunda clasificación. El poeta, hablando de la columna, en la "Introducción", dice:

Mas, dominando aquella procesión tenebrosa, El alba se levanta como una húmeda rosa

Cuyos pétalos caen en una lluvia de oro (54).

Aquí pueden verse tres símbolos, alba, rosa y oro, que significan lo ideal. Atribuye los colores de rosa y oro al alba, colores que la describen justamente. El alba, por dominar la procesión tenebrosa, la humanidad, muestra lo que cree el poeta que es ideal. Lo que sube va hacia lo ideal. Lo que está arriba es el ideal:

La fe es una montaña llena de precipicios.

En sus cavernas moran las larvas de los vicios:

Lo negro es lo monstruoso. Su cuesta es agria y dura.

En todas las montañas sólo la cima es pura (57).

El alba se ve en el cielo, donde está Dios, como dice Lugones: "El cielo es la frente/ De Dios". (54). En los ciclos uno y dos no aparece tanto el alba o la aurora, lo cual significa que mientras el poeta o la Naturaleza desean y sufren sin lograr lo ideal, no ven la gloria del alba: En cambio, en el "Tercer ciclo", donde Lugones describe la gloria que viene tras el sufrir, utiliza más el símbolo del alba. Nótese también que en los ciclos que describen el martirio, estos símbolos se usan en un sentido negativo, tal como "rosas ultrajadas" (6I), "rosa deshojada" (83), o bien como lo deseado, que es el ideal: "el polvo de oro de tus besos" (68). Este ideal no se ve alcanzado hasta el "Tercer ciclo", donde se escribe con mayúscula Oro y también Aurora (IOI). El ideal es deseado a través de todo el libro, pero no llega hasta después del sufrimiento. Otras flores, además de la rosa, también simbolizan lo ideal deseado por el poeta. Donde más se ve expresado este deseo, en el "Primer ciclo" se ven más las flores: azucena (62), magnolias (65), lirio (7x).

Otros símbolos importantes relacionados con el deseo de alcanzar lo ideal son buesos, dientes y esqueletos. Son símbolos algo macabros 
para significar lo ideal, pero se usan en este sentido, como resultados de experiencias directas. Por ejemplo, el poeta describe a la amada como esqueleto y la besa en esta forma: "y me darás tus labios ( $j$ oh tus labios - carnales y sabrosos como frutas - viviendo en tu esqueleto descarnado!)" (68). Una vez alcanzada la unión con ella en forma de es. queleto, y cuando él también sea esqueleto, podrá ser poeta, o divino, que es lo mismo. Cuando ocurra esta unión, verá "unirse nuestros huesos, como rimas" - de una estrofa completa... (68). Usa el verbo en el trempo futuro (porque no es una acción todavía realizada) y ve la unión de buesos como poesía. Lo ideal que él quiere es ser poeta, porque como dice en la "Introducción": "Dios no trabaja en vano" ( 58 ). El ideal, la poesía, es deseado en símbolos desde algo que es bello, como una rosa, hasta lo grotesco, un esqueleto. Es otra muestra de cómo en el cuadro total de la salvación cada miembro tiene un papel. Todo lo más diverso, desde científicos (99), artistas (I00), exploradores (97) , y pueblos (96) va en esta columna que al fin alcanza la Gloria.

El ojo es otro símbolo de lo ideal. Se ve usado muchísimo más en el "Primer ciclo" que en los otros. El poeta, como todavía no ha llegado más allá que desear lo ideal, se describe como persona con malos ojos: "y al fin mis fieros ojos, como un crimen - sobre tus ojos tímidos brillaron..." (64). Los ojos de la amada son "ojos de luz" (64). Aqui hay dos símbolos juntos que expresan lo ideal -ojo y luz. Es notable la diferencia de luz que hay entre la "Introducción" y el "Tercer ciclo", comparada con el "Primer ciclo" y el "Segundo ciclo". En los ciclos intermedios es una luz de estrellas, pues es de noche, mientras que en las otras partes la luz es del sol, de día. Como en el "Tercer ciclo" la fe ha triunfado y los hombres miran a Dios de frente y la luz entra como componente de esta gloria, queda bien claro cómo la diferencia de luz refleja los estados distintos de esta poesía. Cuando es de noche, significando el mal estado del poeta antes de poder participar en la salvación del "Tercer ciclo", es una luz pálida, mientras que al final es una luz deslumbrante.

Con el símbolo de lenguas, en el sentido de idiomas, es donde muy bien está explicada la idea de Las montañas del oro. Las lenguas o son confusas y nadie las entiende o nadie las escucha en la "Introducción" y en los dos primeros ciclos. "Los astros continuaban levantando sus quejas/ Que ninguno sentía sonar en sus orejas" (60). En el "Tercer ciclo" dice: "las piedras y los árboles y las bestias del mundo, levantan al cielo sus almas confusas, en el himno de todas las len- 
guas" (Ior). Lo negativo llega a ser lo positivo. Otros aspectos de Las montañas del oro recuerdan la Biblia y el símbolo de lenguar también hace pensar en la Biblia. El uso de este simbolo recuerda que antes de venir el Espíritu Santo hasta los hombres, nadie se entendía. Pero al descender Dios, lo cual ocurre también en el último ciclo, todo el mundo se entendió. Las vacas, las nubes y los árboles se quejaban, pero en medio de un silencio. Sólo al final escucha todo el mundo y sólo entonces todos se entienden. Completan la simbología de lo ideal los astros y las nubes, símbolos que ya, por su misma situación física, expresan una posición de altura. En el primer ciclo los astros que predominan son la luna y las estrellas, como es natural, siendo de noche. No se menciona el sol ni una vez. En el "Segundo ciclo" el sol aparece en un sentido negativo, tal como "soles extinguidos" (85). Como se podria imaginar, el sol aparece como símbolo en la "Introducción" y en el "Tercer ciclo". El sol se asocia con el símbolo del oro, además, los dos siendo símbolos de lo ideal. El oro y la rosa son símbolos más bien puramente espirituales, mientras que los astros físicamente simbolizan el destino ideal hacia el cual se elevan las montañas y las torres. Las nubes asimismo están físicamente en lo alto. Igual que la montaña que sufre al producir el diamante, las nubes también. El viento empuja las nubes contra los picos de las montañas: "van las nubes a estrellarse en las montañas" (88). Todos los elementos de la Naturaleza juegan su papel, todos entremezclados, para triunfar, siguiendo la fe.

\section{Simbolos de fuerza y movimiento.}

La categoría siguiente de símbolos es la de fuerza y movimiento. Son el viento, el mar y el caballo. La fuerza y el movimiento están en relación directa con el pensamiento de Lugones. Hay que luchar y hay que subir la moniaña para llegar a la cima, donde está el oro del Sol. A la vez el sufrimiento implica un gran esfuerzo físico para dominar lo malo con lo bueno. El martirio no es pasivo, sino una lucha terrible de agonía. Según el poeta, es necesario buscar el martirio; no hay otra manera de llegar.

El mar sufre el mismo martirio que las nubes. "Y la Mar, sus grandes pechos - de sirena echa a la orilla,- - y los muerden los peñascos, -y las ásperas arenas los lastiman" (84). El "Tercer ciclo" da la impresión de más reposo que los otros dos. Después de la lucha de los dos primeros ciclos, el poeta descansa en lo ideal del último ciclo. 


\section{Simbolos de SUfRimiento.}

Simultáneamente a la búsqueda de lo ideal que el poeta describe en los dos primeros ciclos, viene el sufrimiento ya aludido. Hay muchos símbolos que significan este martirio. Los más importantes se refieren a fuego, fragua, borno, llama y brasa. "En las noches luminosas como Ilíadas, surge el lago -tormento de las hogueras... la honda sed, que devorando la gran pompa de sus llamas, - la tortura con febril incandescencia,-- con feroces mordeduras de ascuas rojas" (85). El martirio se representa como pasar por fuego para purificarse. Como sería natural, considerando de lo que tratan los dos primeros ciclos, estos símbolos y los otros en el mismo grupo casi no aparecen en la "Introducción" ni en el "Tercer ciclo". Es curioso notar la semejanza entre el color del oro con el del sol y del fuego. Otra vez se ve que el poeta cree que dentro de cada cosa o de cada ser viviente se encuentra con qué sufrir y con qué salvarse.

Además de los símbolos mencionados arriba, hay otros muchos que significan el martirio, como sangre, bosque o selva (que realmente sufren, simbolizando lo exterior del estado interior del poeta en el primer ciclo), árbol, perro, viuda, vaca y Cristo. Desde lo más noble hasta lo más basto, como se ha visto antes. "Esta es la hora en que los árboles, con sus carnes devoradas por las hachas, - se revisten de misterio... ¡Cómo sufren con sus almas silenciosas..." (8I). "El clamor con que las vacas de la selva-lloran-su duelo" (87). Todo, animal mineral, y vegetal se une en este martirio.

El símbolo del perro es muy significativo en el desarrollo de Las montañas del oro. Aunque aparece muy pocas veces y la mayoría de las veces en un poema en particular, es quizás el mejor símbolo de todo el libro. El perro aparece en el "Primer ciclo" en el poema titulado "Metempsicosis". Este poema en sí es de los mejores del libro y el que mejor explica la visión lugoniana del mundo. Es de noche y sobre un promontorio hay un perro:

Sus colmillos brillaban en la noche--pero sus ojos no, porque era ciego.- Su boca abierta relumbraba, roja-como el vientre caldeado de un brasero;--como la gran bandera de venganza-que corona las iras de mis sueños;- como el hierro de una hacha de verdugo--abrevada en la sangre de los cuellos.-Y en aquella honda 
boca aullaba el hambre,--como el sonido fúnebre en el hueco-de las tristes campanas de Noviembre.-Vi que mi alma con sus brazos yertos-y en su frente una luz hipnotizada - subía hacia la boca de aquel perro,- - y que en sus manos y sus pies sangraban,--como rosas de luz, cuatro agujeros;--y que en la hambrienta boca se perdía-, y que el monstruo sintió en sus ojos secos-encenderse dos llamas, como lívidos-incendios de alcohol sobre los miedos.

Entonces comprendi (;Santa Miseria!)-el misterioso amor de los pequeños;--y odié la dicha de las nobles sedas,- - y las prosapias con raíz de hierro;- $y$ hallé en tu lodo gérmenes de lirios,-y puse la amargura de mis besos-sobre bocas purpúreas, que eran llagas;--y en las prostituciones de tu lecho-vi esparcidas semillas de azucena,-y aprendí a aborrecer como los siervos;-y mis ojos miraton en la sombra-una cruz nueva, con sus clavos nuevos,que era una cruz sin víctima, elevada-sobre el oriente enorme de un incendio,- - aquella cruz sin víctima of recida - como un lecho nupcial. ; $Y$ yo era un perro! (72-73).

El perro siente hambre, igual que el poeta desea lo ideal. Al entrar en su boca el alma del poeta, viene la luz sobre sus ojos que antes no veían. Cuando lo que puede salvar -en este caso el alma del poetaentra en un cuerpo tan bajo, el perro se transforma. El poeta tiene la misma función que Jesús. Cristo se hizo hombre para redimir a la humanidad. El poeta se hace perro para salvar a la humanidad. El poeta ahora comprende que en un cuerpo vil hay que salvarse. No sólo lo que es noble se salva, sino lo que es innoble, también. La referencia a Cristo se hace más evidente cuando el perro está sangrando como si estuviese clavado a la cruz. El poeta, al bajarse al cuerpo del perro, tendrá que sufrir igual que Jesucristo. Por eso, cuando ve la cruz nueva sin victima ofrecida y dice, "iY yo era un perro!" dice que él, al ofrecerse como la víctima para salvarse a sí mismo y a la naturaleza y a la humanidad en general, jugará el mismo papel que Cristo. Es muy significativo este poema, pues aquí mismo el poeta se da cuenta de la única manera de alcanzar la gloria del "T'ercer ciclo", que es subiendo la cuesta, luchando por llegar a la cima y sufriendo el martirio de todas las cosas, sufriéndolo en los elementos de la Naturaleza. Es el único modo de expiar. Habrá que recordar que antes de esto el poeta se consideraba muy vil y no digno de alcanzar la amada, por lo mucho que la deseaba.

Además este poema sirve de enlace entre el "Primer ciclo" y el "Se- 
gundo ciclo". El segundo empieza con "El hijo del hombre", que es una descripción de Jesús en el desierto durante su Pasión. Desde este punto toda la Naturaleza empieza su martirio, un elemento causando el martirio del otro. El viento castiga las nubes, empujándolas contra las moniañas (88), el mar sufre al romperse en la costa dentellada (84), y la montaña sufre al esforzarse en producir un diamante del carbón (85).

Así en este poema "Metempsicosis" se resume todo lo que ha venido antes -el deseo del poeta de llegar a Dios, a lo ideal, encima de la Torre de Oro, y cómo ha de hacerlo.

\section{Símbolos de lo bajo.}

Los símbolos de lo bajo, moral y físicamente, con sombra y tinieblas, la noche, negro: " $\mathrm{Ah}$, cuando oigas hablar de esas angustias... diles que existe un lóbrego paraje - en la infinita latitud de mi alma,- - con silenciosas noches de seis meses" (66). También son símbolos antro o cueva y abismo: "Caímos a un abismo tan profundo- que alli no había Dios" (63). Casi todos se encuentran más en los dos primeros ciclos, en contraste con varios de los símbolos de lo ideal que se encuentran de una manera positiva en la "Introducción" y el "Tercer ciclo", o como lo no alcanzado o algo negativo en el "Primer ciclo" o el segundo. Así se ve el contraste de la sombra y tineblas, noche y negro con el sol, oro, luz y alba. También el abismo se contrasta con la cima. La figura de la montaña del título muestra el abismo, la nocbe y lo negro que está allá abajo. En la cima se ve la luz dorada del Sol. Por eso la montaña es símbolo muy adecuado para expresar la visión lugoniana del mundo. La montaña en su base sugiere lo bajo (el estado del ánimo del poeta antes de empezar su martirio). La cuesta sugiere el esfuerzo dinámico realizado en el mar:tirio. La cima sugiere lo puro del ideal que el poeta realiza después de subir la montaña, siguiendo el camino arduo de la fe.

\section{Símbolos QUE SE REFIEREN A ESTímULOS PARA SUFRIR.}

La última categoría incluye los símbolos que incitan el sufrimiento. Los otros en su mayoria han sido símbolos visuales. Estos no lo son. La espuela se refiere al tacto. La campana, el clarin y la trompeta son auditivos. Llaman al combate que es otro nombre para el martirio. Las uñas y la hoz y hacha, símbolos táctiles, se asocian más con el dolor del martirio. 
Describiendo a la amada, escribe Lugones: "dame tus uñas, dagas de oropara sufrir tu posesión maldita" (62). Describiendo los árboles sufriendo los golpes de las hachas, escribe el poeta: "su plañido que se queja del martirio de las hachas" (8I). En el "Primer ciclo", cuando el poeta se refiere sólo a sí mismo, son uñas lo que le hacen sufrir. Más tarde, en el "Segundo ciclo", cuando el mundo fuera del poeta sufre, son bachas lo que provocan el sufrimiento. Ambos instrumentos, hacha y $u \tilde{n} a$, ocasionan el mismo grado de dolor. La diversidad de tamaño se debe a la diferencia dimensional de las criaturas martirizadas. Una garra de uñas basta para destrozarle las carnes a un ser humano. Se necesita, sin embargo, una bacba para herir un árbol.

Las trompetas prometen la realización del deseo:

Ya cantan a las huestes soberanas

El pregón victorioso de las dianas,

Con sus claras gargantas las trompetas. $\left(7^{6}\right)$

Todos estos simbolos de las seis categorías son significativos para entender las ideas de Lugones. Cuándo se usan y cómo se usan es muy importante también. El uso de los símbolos bajos y los de martirio en los dos primeros ciclos refuerza la descripción que hace el poeta de su estado psicológico y del de la Naturaleza. El uso de los símbolos del ideal refleja el estado del poeta ante el ideal -como cosa fuera del alcance o bien negativa en los dos primeros ciclos, o como ya realizado en el "Tercer ciclo".

Todos estos símbolos tomados en conjunto muestran las creencias de Lugones en Las montañas del oro. El poeta ama lo ideal. El poeta es lo ideal y así se ama a sí mismo, como dice en "Laudatorio a Narciso". El poeta es divino; el poeta es Dios y Dios es el poeta. Así, el poeta tiene la misma función que Dios que se hizo hombre, sufrió, murió y resucitó. El poeta se hace perro y redime a todos los seres vivientes, hasta los no vivientes. La venganza del mundo pidió el martirio de Jesús y pide lo mismo del poeta. Por eso, tanto el poeta como la Naturaleza se martirizan. Todo se compone de carne y espíritu, no sólo el poeta, sino las piedras. Todo, desde lo alto hasta lo bajo, sufre en nombre del poeta y el poeta en nombre de ellos. Todo se salva pasando por la experiencia del martirio. El ideal, que es su redención, es lo que desea el poeta en la "Introducción"; el ideal es lo que le llega en el "Himno de las Torres".

La vida, vista como un esfuerzo dinámico en la escuela simbolista, 
tiene una expresión personal en la poesía de Leopoldo Lugones. Para él, el dinamismo es sugerido a través de símbolos que explican su lugar dentro del simbolismo. El proceso dinámico, común a los poetas de esa época, se revela en Lugones como un deseo de lo ideal que sólo se verifica sufriendo, para después permanecer inquebrantablemente como culminación depurada de su visión vital.

University of Pittsburgh

\author{
ANNA W. AshHurst
}

